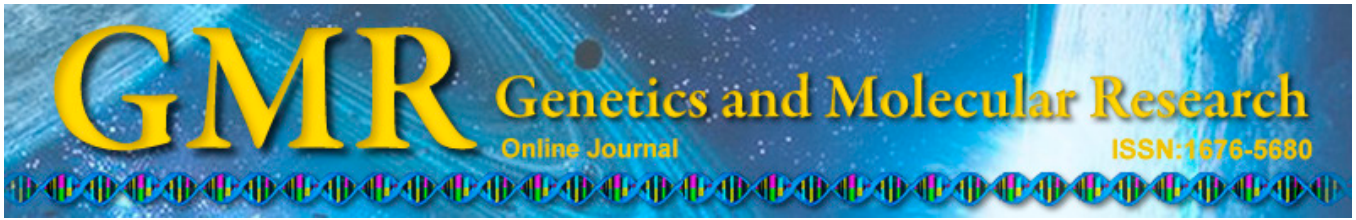

\title{
Association of SSR markers with contents of fatty acids in olive oil and genetic diversity analysis of an olive core collection
}

\author{
M. Ipek ${ }^{1}$, A. Ipek ${ }^{1}$, M. Seker ${ }^{2}$ and M.K. Gul ${ }^{3}$ \\ ${ }^{1}$ Department of Horticulture, Faculty of Agriculture, Uludag University, \\ Bursa, Turkey \\ ${ }^{2}$ Department of Horticulture, Faculty of Agriculture, Sirnak University, \\ Sirnak, Turkey \\ ${ }^{3}$ Sales and Marketing Manager, EuroChem Agro, Istanbul, Turkey \\ Corresponding author: A. Ipek \\ E-mail:maipek@uludag.edu.tr
}

Genet. Mol. Res. 14 (1): 2241-2252 (2015)

Received March 19, 2014

Accepted July 1, 2014

Published March 27, 2015

DOI http://dx.doi.org/10.4238/2015.March.27.10

\begin{abstract}
The purpose of this research was to characterize an olive core collection using some agronomic characters and simple sequence repeat (SSR) markers and to determine SSR markers associated with the content of fatty acids in olive oil. SSR marker analysis demonstrated the presence of a high amount of genetic variation between the olive cultivars analyzed. A UPGMA dendrogram demonstrated that olive cultivars did not cluster on the basis of their geographic origin. Fatty acid components of olive oil in these cultivars were determined. The results also showed that there was a great amount of variation between the olive cultivars in terms of fatty acid composition. For example, oleic acid content ranged from 57.76 to $76.9 \%$ with standard deviation of $5.10 \%$. Significant correlations between fatty acids of olive oil were observed. For instance, a very high negative correlation (-0.812) between oleic and linoleic acids was detected. A structured association analysis between the content of fatty acids in olive oil and SSR markers was performed. STRUCTURE analysis assigned olive cultivars to two
\end{abstract}


gene pools $(K=2)$. Assignment of olive cultivars to these gene pools was not based on geographical origin. Association between fatty acid traits and SSR markers was evaluated using the general linear model of TASSEL. Significant associations were determined between five SSR markers and stearic, oleic, linoleic, and linolenic acids of olive oil. Very high associations $(\mathrm{P}<0.001)$ between ssrOeUA-DCA14 and stearic acid and between GAPU71B and oleic acid indicated that these markers could be used for marker-assisted selection in olive.

Key words: Olive (Olea europaea L.); Fatty acids; Association mapping; STRUCTURE analysis; Simple sequence repeat; Genetic relationships

\section{INTRODUCTION}

Olive (Olea europaea L.) is an economically important fruit and oil crop in the Mediterranean region where it has been cultivated since ancient times. This species is a member of the family Oleaceae, which contains about 30 genera and 600 species (Bracci et al., 2011). Olive has been considered to be one of the most diverse tree species with about 1200 olive cultivars grown worldwide (Bartolini et al., 1998). The characterization of olive germplasm has been mainly carried out by using morphological and agronomic characters (Cantini et al., 1999), but most of them used for the characterization of olive genotypes can be affected by environmental factors which could lead to misidentification and incorrect naming of olive genotypes (Ipek et al., 2012; Kaya et al., 2013). Therefore, DNA molecular markers, which only reflect nucleotide diversity in the genome of genotypes, have been utilized to estimate genetic relationships between olive genotypes and cultivars in most of the recent genetic diversity studies (reviewed by Bracci et al., 2011). Assessment of genetic diversity based on both morphological and molecular markers and their comparisons were also reported in recent studies (Corrado et al., 2009; D'Imperio et al., 2011).

Simple sequence repeat (SSR; microsatellites) is one of the most commonly used DNA molecular markers for revealing genetic diversity between olive genotypes (Sarri et al., 2006; Ipek et al., 2009; Işı et al., 2011). SSR markers developed for the olive genome were proven to be highly polymorphic and useful for olive genetic diversity assessment (Sefc et al., 2000; Carriero et al., 2002; Cipriani et al., 2002; De La Rosa et al., 2002; Díaz et al., 2006; Sarri et al., 2006; Baldoni et al., 2009). They have been preferred in recent genetic diversity studies in olive because of their high degree of repeatability, polymorphism, and multiple alleles in a single locus although their development cost is high compared to other PCR-based marker systems such as random amplified polymorphic DNA (RAPD) and amplified fragment length polymorphism (AFLP).

Olives are consumed as both table olive and oil olive. The cultivars with large fruits and high fruit flesh/stone ratio are generally utilized as table olives while the cultivars with high oil content and quality are usually used for oil extraction. Olive oil is an important dietary complement in the Mediterranean basin and its consumption has been increasing in other parts of the world due to the recognition of its health benefits (Pinelli et al., 2003; Di Bella et al., 2007). Olive cultivars differ in terms of their oil yield and quality. Both genetic and environmental factors can contribute to the variations observed in olive oil content between cultivars (Mannina et al., 2003; Di Bella et al., 2007). The quality of olive oil is usually determined according to its fatty acid composition, phenolic, phytosterol, and tocopherol contents, acidity, UV absorbance and 
peroxide value. The quality parameters of olive oil also demonstrate great variations between olive genotypes, and different factors such as geographical location, cultural practices, extraction procedures and genetics also significantly contribute to this variation (Mailer et al., 2010).

Olive has very long juvenile period which restricts breeding programs in olive (El Bakkali et al., 2013). Some cross-breeding efforts in olive during the last decades have been initiated to develop new cultivars and segregating populations for evaluation of the genetic basis of agronomic characters (Fabbri et al., 2009). In addition, some recent studies have reported on the construction of olive core collections and their utilization in association mapping (Belaj et al., 2012; Díez et al., 2012; El Bakkali et al., 2013). It has been demonstrated that it is possible to identify DNA markers linked to traits of interest in fruit crops by association mapping (Forcada et al., 2013). Recently, some studies also reported the association of DNA markers with important morpho-agronomic traits in some fruit species by using germplasm collections (Kar et al., 2008). However, to date, there is no report on the association of molecular markers with any agronomic character or fatty acid composition of olive oil to our knowledge. In plants, especially in fruit crops, the development and use of molecular markers linked to trait of interest has become an important issue in breeding programs because of the long juvenile period in most of the fruit cops. The markers tightly linked to or significantly associated with agronomic traits could be useful in olive breeding programs to reduce time and cost, which are the major drawbacks of olive breeding programs.

The aims of this study were to characterize an olive core collection consisting of commercial cultivars using fatty acid composition of olive oil and SSR markers and to determine SSR markers significantly associated with fatty acid content of olive oil.

\section{MATERIAL AND METHODS}

\section{Plant material}

A total of 22 olive cultivars maintained at the Experimental Plot of the Olive Production Station of the Turkish Ministry of Agriculture and Rural Affairs, Edremit, Balikesir, Turkey were used for analysis of fatty acid composition and SSR polymorphisms (Table 1). The trees of each accession were more than 20-years-old and under optimum cultivation.

\section{Fruit sampling}

Fruits were collected from three trees of each cultivar on the same day. A total of 100 fruit samples from each tree were picked when $75 \%$ of the fruits were colored pink/purple on trees. Fruits were harvested from the beginning of December to the end of January for two consecutive growing seasons. The optimum maturity stage of olive cultivars was determined by grouping the olives into skin and flesh color, and then applying a maturity index as indicated by Boskou (2002). The maturity index of the analyzed cultivars ranged between 2.4 and 3.8 (data not presented).

\section{Fatty acid composition analysis}

Olive oil from the fruit samples was extracted as described by Şeker et al. (2008). Fatty acid methyl esters of extracted oil samples were obtained by using the method of the Interna- 
tional Olive Council, COI/T.20/Doc. 24 (http://www.internationaloliveoil.org). Fatty acid composition of olive oil was determined by using a Perking-Elmer 8420 gas chromatograph (San Jose, USA) equipped with flame ionization detector and capillary column (DB-S, $15 \mathrm{~mm} \times 15 \mathrm{~m}$ x $0.25 \mathrm{~mm} \times 0.1 \mathrm{~mm}$ ). The column and injector temperatures were 250 and $220^{\circ} \mathrm{C}$, respectively. $\mathrm{H}_{2}$ He and air flows were 40,45 , and $450 \mathrm{~mL} / \mathrm{min}$, respectively. Pearson correlations between fatty acid content levels were calculated using the SPSS v.20 program with two-tailed option checked. Descriptive statistical values were also calculated with the SPSS program.

\section{SSR analysis}

DNA samples were extracted from $20 \mathrm{mg}$ freeze-dried leaf samples using the DNeasy Plant Mini kit (Qiagen, Germany). The concentration of each DNA sample was measured using a Qubit fluorometer (Invitrogen, USA) and adjusted to $30 \mathrm{ng} / \mu \mathrm{L}$ for PCR. Twenty previously developed SSR primer pairs were used for the amplification of SSR markers among 22 olive cultivars (Table 2). Forward primers were tailed with the M13 sequence (GACGTTGTA AAACGACGGCC) at the 5 ' end (Schuelke, 2000). Each $20-\mu$ L PCR mixture for the amplification of SSR markers contained 1.0 U Taq DNA polymerase (Thermo Scientific, USA), 1X reaction buffer, $0.10 \mu \mathrm{M}$ M13 sequence tailed forward primer, $0.20 \mu \mathrm{M}$ reverse primer, $0.20 \mu \mathrm{M}$ M13 primer labeled with LI-COR infrared dye either at $700 \mathrm{~nm}$ or $800 \mathrm{~nm}$ (LI-COR, USA), 0.25 $\mathrm{mM}$ dNTPs, and $45 \mathrm{ng}$ DNA. The thermal cycling conditions were as follows: $2 \mathrm{~min}$ at $94^{\circ} \mathrm{C} ; 6$ cycles of $45 \mathrm{~s}$ at $94^{\circ} \mathrm{C}, 1 \mathrm{~min}$ at $61^{\circ} \mathrm{C}$ (annealing temperature was reduced $1{ }^{\circ} \mathrm{C}$ after every cycle for touchdown PCR protocol), and $1 \mathrm{~min}$ at $72^{\circ} \mathrm{C} ; 28$ cycles of $45 \mathrm{~s}$ at $94^{\circ} \mathrm{C}, 1 \mathrm{~min}$ at $55^{\circ} \mathrm{C}$, and $1 \mathrm{~min}$ and $10 \mathrm{~s}$ at $72^{\circ} \mathrm{C} ; 7$ cycles of $45 \mathrm{~s}$ at $94^{\circ} \mathrm{C}, 1 \mathrm{~min}$ at $54^{\circ} \mathrm{C}$, and $1 \mathrm{~min}$ and $10 \mathrm{~s}$ at $72^{\circ} \mathrm{C}$; and a final extension step of 15 min at $72^{\circ} \mathrm{C}$. PCR was performed using a GenAmp 2720 Thermal Cycler (Applied Biosystems, USA). The PCR products were separated on 6\% polyacrylamide gels at $30 \mathrm{~W}$ for 2 to $3 \mathrm{~h}$ using a LI-COR 4300 automated sequencer system (LI-COR).

\section{Data analysis}

A genetic similarity matrix of olive genotypes based on SSR markers was computed using the Dice coefficient (Dice, 1945), while a Euclidean distance matrix was calculated using the data of fatty acid composition of olive oil (Sneath and Sokal, 1973). Unweighted pair group method with arithmetic averages (UPGMA) dendrograms based on these matrices were constructed using the NTSYSpc v.2.21 program (Exeter Software, New York). Principal component analysis (PCA) was carried out according to the procedure described in the NTSYSpc program. Heterozygosity $\left(H_{\mathrm{E}}\right)$ and the polymorphic information content (PIC) values for SSR markers were calculated using PIC Calculator Extra.

Three SSR markers (UDO99-04, GAPU59, and EMO30) were present at more than one locus in the olive genome and these markers were excluded from the subsequent analyses since allelic constitutions of these markers were not known in this population. Linkage disequilibrium (LD) between each pair of SSR loci was calculated using Trait Analysis by the Association, Evolution and Linkage (TASSEL) software v2.1 (Bradbury et al., 2007). The significance level (P value) of LD for each pair of loci was examined by 10,000 permutations using the "rapid permutation" option. Population structure of olive genotypes used in this study was assessed using a model-based Bayesian clustering implemented in STRUCTURE v.2.3.4 (Pritchard et al., 2000). Possible Ks (an assumed fixed number of subpopulations in the entire population) from 1 to 10 were examined with 5 replicates. Each replication run was conducted 
with the burn-in period of 100,000 steps followed by 100,000 Monte Carlo Markov Chain (MCMC) replications using an admixture model and correlated allele frequencies options. The most likely number of subpopulations $(\mathrm{K})$ was determined using the method described by Evanno et al. (2005). The proportion of membership (Q matrix) value of each individual in each subpopulation was also calculated. All genotypes were assigned to the subpopulation according to the largest estimates of probability by the program.

Association between phenotypic traits and SSR markers were evaluated using the general linear model (GLM) of TASSEL. In GLM, SSR markers were fitted as fixed effects and the population membership estimates (Q matrix) from STRUCTURE analysis as covariates. $\mathrm{P}$ values were generated for each trait with 1000 permutations of genotypes.

\section{RESULTS AND DISCUSSION}

\section{SSR marker analysis and genetic relationships between the olive cultivars}

Genetic relationships between 22 olive cultivars from Turkey, Spain, Italy, and France were assessed using SSR markers and a total of 136 polymorphic SSR alleles were generated by 20 primer combinations (Table 2). The number of polymorphic alleles of SSR markers ranged from 2 (EMOL) to 10 (ssrOeUA-DCA04, ssrOeUA-DCA09 and GAPU59) with an average of 6.8 polymorphic SSR alleles per primer combination. $H_{\mathrm{E}}$ ranged from 0.5 to 0.86 , PIC varied from 0.37 to 0.84 (Table 1). In another study, Fendri et al. (2010) found that $H_{\mathrm{E}}$ ranged from 0.54 to 0.82 and PIC varied from 0.48 to 0.79 . Similar PIC and $H_{\mathrm{E}}$ values for SSR markers in olive were also reported by Noormohammadi et al. (2007).

Table 1. Origins and fatty acid composition of olive oil and their descriptive statistics. Mean values are expressed in percentages.

\begin{tabular}{|c|c|c|c|c|c|c|c|c|c|}
\hline Cultivars & Origin & $\begin{array}{c}\text { Oleic } \\
\text { acid }\end{array}$ & $\begin{array}{l}\text { Palmitic } \\
\text { acid }\end{array}$ & $\begin{array}{l}\text { Linoleic } \\
\text { acid }\end{array}$ & $\begin{array}{l}\text { Stearic } \\
\text { acid }\end{array}$ & $\begin{array}{l}\text { Palmitoleic } \\
\text { acid }\end{array}$ & $\begin{array}{l}\text { Linolenic } \\
\text { acid }\end{array}$ & $\begin{array}{l}\text { Arachidic } \\
\text { acid }\end{array}$ & $\begin{array}{c}\text { Myristic } \\
\text { acid }\end{array}$ \\
\hline Arbequina & Spain & 65.56 & 19.57 & 11.63 & 0.80 & 2.17 & 0.56 & 0.23 & 0.027 \\
\hline Ascolana & Italy & 70.14 & 15.49 & 10.49 & 1.01 & 1.06 & 0.53 & 0.76 & 0.033 \\
\hline Ayvalik & Turkey & 68.00 & 16.05 & 12.63 & 1.00 & 1.12 & 0.68 & 0.34 & 0.045 \\
\hline Cakir Yaglik & Turkey & 75.14 & 11.92 & 9.88 & 1.06 & 0.49 & 0.81 & 0.29 & 0.044 \\
\hline Domat & Turkey & 63.07 & 17.25 & 15.44 & 1.39 & 0.98 & 0.94 & 0.55 & 0.015 \\
\hline Edincik Su & Turkey & 58.60 & 16.75 & 20.83 & 0.98 & 1.68 & 1.08 & 0.29 & 0.064 \\
\hline Erkence & Turkey & 68.21 & 13.82 & 14.49 & 1.45 & 0.58 & 0.72 & 0.35 & 0.037 \\
\hline Gemlik & Turkey & 72.8 & 16.18 & 7.81 & 1.17 & 0.57 & 0.68 & 0.4 & 0.037 \\
\hline Gordales & Spain & 71.08 & 14.15 & 10.69 & 1.07 & 0.81 & 1.19 & 0.34 & 0.036 \\
\hline Hojiblanca & Spain & 76.00 & 12.62 & 7.85 & 1.41 & 0.46 & 0.91 & 0.34 & 0.031 \\
\hline Karamursel Su & Turkey & 57.76 & 11.10 & 27.83 & 0.96 & 0.17 & 1.20 & 0.32 & 0.039 \\
\hline Kiraz & Turkey & 71.23 & 14.05 & 11.92 & 0.79 & 0.63 & 0.81 & 0.30 & 0.023 \\
\hline Leccino & Italy & 70.12 & 17.16 & 9.00 & 1.06 & 1.60 & 0.58 & 0.28 & 0.040 \\
\hline Lucques & France & 64.3 & 12.37 & 8.69 & 3.01 & 0.74 & 0.16 & 0.35 & 0.026 \\
\hline Manzanilla & Spain & 63.58 & 18.58 & 14.45 & 1.10 & 1.19 & 0.91 & 0.33 & 0.017 \\
\hline Memecik & Turkey & 70.84 & 15.31 & 10.96 & 0.89 & 0.86 & 0.76 & 0.33 & 0.006 \\
\hline Memeli & Turkey & 71.65 & 14.17 & 11.10 & 1.18 & 0.6 & 0.75 & 0.33 & 0.024 \\
\hline Negral & Spain & 76.09 & 15.71 & 4.21 & 1.22 & 1.61 & 0.87 & 0.43 & 0.021 \\
\hline Samanli & Turkey & 74.49 & 11.18 & 10.22 & 0.76 & 1.87 & 1.11 & 0.29 & 0.031 \\
\hline Tavsan Yuregi & Turkey & 66.81 & 13.92 & 9.94 & 3.00 & 1.07 & 0.24 & 0.32 & 0.028 \\
\hline Uslu & Turkey & 70.32 & 13.49 & 13.26 & 0.77 & 1.09 & 0.86 & 0.20 & 0.039 \\
\hline Verdial & Spain & 70.55 & 17.61 & 10.91 & 1.58 & 1.33 & 0.47 & 0.35 & 0.040 \\
\hline Minimum & - & 57.76 & 11.10 & 4.21 & 0.76 & 0.17 & 0.16 & 0.20 & 0.006 \\
\hline Maximum & - & 76.09 & 19.57 & 27.83 & 3.01 & 2.17 & 1.20 & 0.76 & 0.064 \\
\hline Mean & - & 68.92 & 14.93 & 12.01 & 1.26 & 1.03 & 0.76 & 0.35 & 0.032 \\
\hline SD & - & 5.10 & 2.36 & 4.83 & 0.61 & 0.51 & 0.27 & 0.11 & 0.012 \\
\hline
\end{tabular}


Table 2. Number of polymorphic alleles, heterozygosity $\left(H_{\mathrm{E}}\right)$ and polymorphic information content (PIC) of 20 SSR loci.

\begin{tabular}{|c|c|c|c|c|}
\hline & SSR markers & No. of alleles & $H_{\mathrm{E}}$ & PIC \\
\hline 1 & ssrOeUA-DCA09a & 10 & 0.79 & 0.77 \\
\hline 2 & ssrOeUA-DCA14 ${ }^{\mathrm{a}}$ & 5 & 0.71 & 0.65 \\
\hline 3 & ssrOeUA-DCA16 & 5 & 0.67 & 0.61 \\
\hline 4 & ssrOeUA-DCA18 & 9 & 0.81 & 0.79 \\
\hline 5 & ssrOeUA-DCA4 ${ }^{a}$ & 10 & 0.85 & 0.83 \\
\hline 6 & EMO190 & 6 & 0.75 & 0.72 \\
\hline 7 & $\mathrm{EMO}^{\mathrm{b}}$ & 7 & 0.74 & 0.71 \\
\hline 8 & $\mathrm{EMOL}^{\mathrm{b}}$ & 2 & 0.50 & 0.37 \\
\hline 9 & GAPU101 ${ }^{\mathrm{c}}$ & 7 & 0.82 & 0.79 \\
\hline 10 & GAPU103 ${ }^{\circ}$ & 4 & 0.54 & 0.46 \\
\hline 11 & GAPU12 ${ }^{c}$ & 8 & 0.78 & 0.75 \\
\hline 12 & ${\text { GAPU } 59^{c}}^{c}$ & 10 & 0.86 & 0.84 \\
\hline 13 & GAPU71B $^{c}$ & 7 & 0.79 & 0.76 \\
\hline 14 & UDO99-04 ${ }^{\mathrm{d}}$ & 5 & 0.74 & 0.69 \\
\hline 15 & UDO99-06 ${ }^{\mathrm{d}}$ & 8 & 0.80 & 0.77 \\
\hline 16 & UDO99-17 & 6 & 0.78 & 0.75 \\
\hline 17 & UDO99-25 & 7 & 0.81 & 0.78 \\
\hline 18 & UDO99-39d & 6 & 0.71 & 0.67 \\
\hline 19 & UDO99-42d & 5 & 0.73 & 0.69 \\
\hline \multirow[t]{2}{*}{20} & UDO99-43 & 9 & 0.83 & 0.81 \\
\hline & Average & 6.8 & 0.75 & 0.71 \\
\hline
\end{tabular}

Developed by ${ }^{\mathrm{a}} \mathrm{Sefc}$ et al. (2000), ${ }^{\mathrm{b}} \mathrm{De}$ la Rosa et al. (2002), ${ }^{\mathrm{c} C a r r i e r o}$ et al. (2002), and ${ }^{\mathrm{d}}$ Cipriani et al. (2002).

A UPGMA dendrogram demonstrating genetic relationships between 22 olive cultivars was developed using a genetic similarity matrix based on the Dice coefficient (Figure 1). According to the UPGMA dendrogram, there was no obvious clustering based on the geographical origins of olive cultivars. For example, 'Karamursel Su' (Turkey) and 'Gordales' (Spain) were closely related cultivars in this study. Similarly, 'Negral' (Spain), 'Lucques' (France) and 'Tavsan Yuregi' (Turkey) clustered together. Although it was not apparent, cultivars from Spain and Italy clustered together and cultivars from Turkey grouped together. This weak correlation between genetic relationship and geographical origin of olive cultivars was also reported by Sarri et al. (2006).

Recently, a consensus list of microsatellite markers for olive genotyping was published by Baldoni et al. (2009). The authors suggested 11 SSR markers for genotyping olive cultivars. In this study, we were able to use nine of these SSR markers. A total of 66 polymorphic alleles from nine consensus SSR markers were observed among 22 olive cultivars. Using these 66 SSR markers, another UPGMA dendrogram was developed using the genetic similarity matrix based on the Dice coefficient (Figure 1). These nine SSR markers were sufficient to discriminate all olive cultivars from each other, and the dendrogram based on 20 SSR markers was very similar to that of nine consensus SSR markers. Dice similarity matrices based on 20 SSR markers and nine SSR markers were compared using the matrix comparison plot program in NTSYSpc v.2.21 with normalize Mantel statistics checked, and the correlation between these matrices was very high $(\mathrm{r}=0.817)$. This result suggested that consensus SSR markers were sufficient to assess genetic relationships among the olive cultivars.

\section{Fatty acid composition of olive oil and the correlation among fatty acids}

Oleic acid was the highest fatty acid in the composition of olive oil of all cultivars with a mean value of $68.92 \%$, and it was followed by palmitic (14.93\%) and linoleic (12.01\%) 

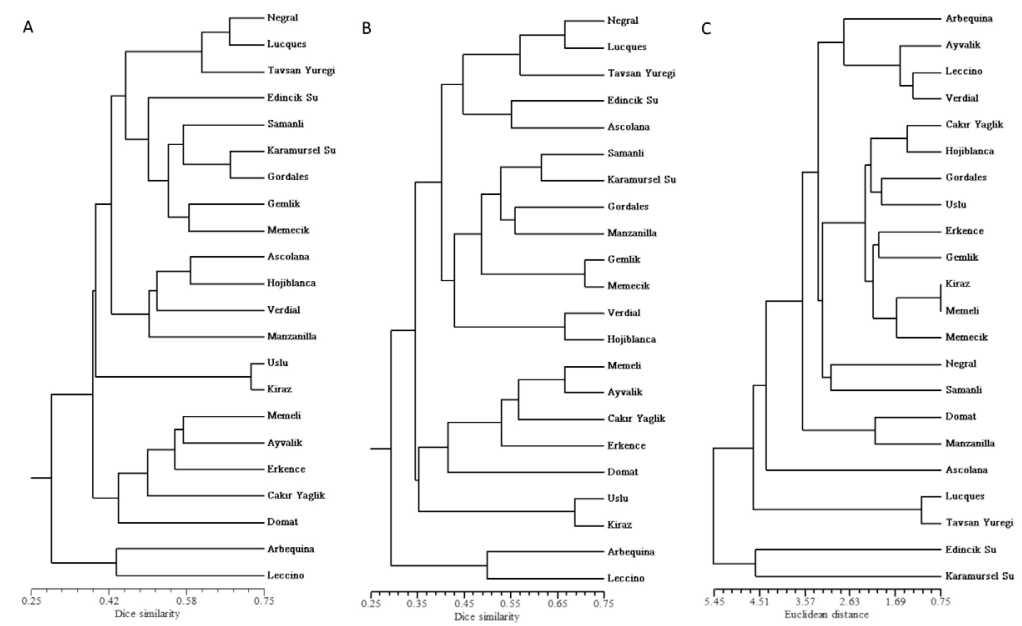

Figure 1. UPGMA dendrograms based on A 20 SSR markers; B nine consensus SSR markers and; C fatty acid composition of olive oil.

acids (Table 1). The total of these three fatty acids represented more than $95 \%$ of olive oil. There was a high degree of variation between olive cultivars regarding the fatty acid composition of their oil. For example, oleic acid content of these olive cultivars ranged from $57.76 \%$ (Karamursel $\mathrm{Su}$ ) to $76.9 \%$ (Negral) with a standard deviation of $5.1 \%$. Variation in linoleic acid content was the highest and it varied from $4.21 \%$ (Negral) to $27.83 \%$ (Karamursel $\mathrm{Su}$ ) with standard deviation of $4.83 \%$. A high degree of variation in the fatty acid composition of olive oil was also reported by previous studies (Mannina et al., 2003; Di Bella et al., 2007; D'Imperio et al., 2007). Similarly, oleic acid was the highest component of olive oil, followed by the palmitic and linoleic acids, in those studies.

Significant correlations between the fatty acids of olive oil were detected (Table 3). There was a very high negative correlation $(-0.812)$ between oleic and linoleic acids while linoleic acid was positively correlated $(0.458)$ with linolenic acid. Although oleic and linoleic acids were synthesized by the desaturation of carbon bonds of stearic acid, no significant correlation was found between stearic acid and oleic acid or linoleic acid. However, stearic acid negatively correlated (-0.684) with linolenic acid. Palmitic and palmitoleic acids were also positively correlated ( 0.555$)$. A significant negative correlation between oleic and linoleic acids and significant positive correlation between palmitic and palmitoleic acids were also reported in another study (León et al., 2004).

Table 3. Correlation coefficients between fatty acids of olive oil.

\begin{tabular}{|c|c|c|c|c|c|c|c|}
\hline & Oleic acid & Linoleic acid & Palmitic acid & Linolenic acid & Arachidic acid & Myristic acid & Palmitoleic acid \\
\hline Linoleic acid & $-0.812 * *$ & & & & & & \\
\hline Palmitic acid & -0.222 & -0.086 & & & & & \\
\hline Linolenic acid & -0.049 & $0.458^{*}$ & -0.201 & & & & \\
\hline Arachidic acid & 0.027 & -0.118 & 0.135 & -0.127 & & & \\
\hline Myristic acid & -0.182 & 0.320 & -0.098 & 0.142 & -0.204 & & \\
\hline Palmitoleic acid & -0.036 & -0.192 & $0.555^{* *} *$ & -0.081 & -0.127 & 0.080 & \\
\hline Stearic acid & -0.161 & -0.226 & -0.169 & $-0.684 * *$ & 0.077 & -0.124 & -0.173 \\
\hline
\end{tabular}

**Correlation is significant at the 0.01 level (2-tailed). ${ }^{*}$ Correlation is significant at the 0.05 level (2-tailed). 
The UPGMA dendrogram based on Euclidian distances of the fatty acid content of olive oils was also constructed to demonstrate a relationship between olive cultivars (Figure 1). However, groupings of olive cultivars based on the SSR markers and fatty acid content of olive oils were not similar. This could be due to few traits (eight fatty acids) used for clustering of olive cultivars compared to 136 polymorphic SSR alleles used for clustering. However, Corrado et al. (2009) indicated that the differentiation power of morphological traits was low in their study, even if they used 35 morphological descriptors.

PCA based on fatty acid composition of olive oil demonstrated that 'Karamursel Su' and 'Edincik Su' separated from the rest of the cultivars with highest linoleic and linolenic acid contents (Figure 2). Similarly, 'Arbequina' was distinctly placed on the graph because it had the highest palmitic and palmitoleic acid contents. On the other hand, 'Lucques' and 'Tavsan Yuregi' were differentiated from the rest of the cultivars by having the lowest stearic and oleic acid contents.

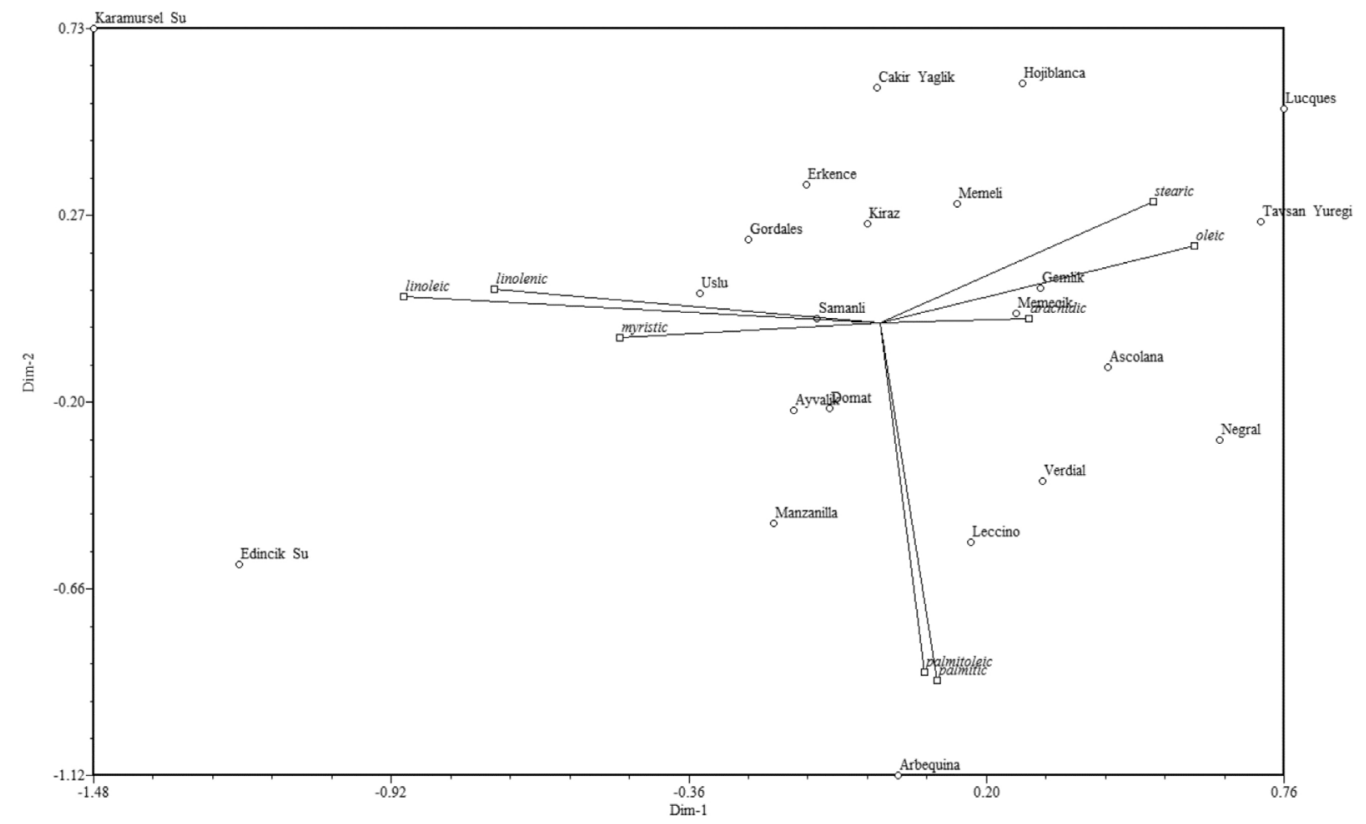

Figure 2. PCA analysis based on fatty acid contents of 22 olive cultivars.

\section{Association of SSR markers with fatty acid content of olive oil}

Significant LD was detected between ssrOeUA-DCA09 and ssrOeUA-DCA4 (P < 0.01), ssrOeUA-DCA16 and UDO99-24 ( $<0.01$ ), and UDO99-06 and ssrOeUA-DCA14 $(\mathrm{P}<0.001)$ SSR loci. It has been indicated that a structured association mapping analysis could reduce the detection of false associations of molecular markers with traits if population structure was included in the analysis. Most likely, the number of gene pools indicated by the STRUCTURE analysis in this study was estimated to be $\mathrm{K}=2$ with the highest $\Delta \mathrm{K}$ value (9.20) and it was followed by $\mathrm{K}=4$ and $\mathrm{K}=3$ with $\Delta \mathrm{Ks}$ of 6.16 and 2.39 , respectively 
(Table 4, Figure 3). For $\mathrm{K}=2,3$ and 4, olive accessions from different regions of the world were assigned to the same gene pools. For example, 'Tavsan Yuregi' from Turkey, 'Lucques' from France and 'Negral' from Spain were always placed in the same gene pool. Similarly, 'Ayvalık', 'Cakır Yaglik', 'Erkence', 'Gemlik' and 'Memeli' from Turkey, 'Arbequina' from Spain and 'Leccino' from Italy were assigned to the same gene pool for all Ks. However, gene pools started to become inseparable with increasing $\mathrm{K}$ values (Figure 3). In two recent studies to construct an olive core collection for association mapping, the most likely gene pools in olive populations were estimated by the STRUCTURE analysis. Similarly, Belaj et al. (2012) found most likely genetic structure as $\mathrm{K}=2$ and clustered 361 olive genotypes from 19 countries into two gene pools. On the other hand, El Bakkali et al. (2013) found $\mathrm{K}=3$ as the most likely number of gene pools and assigned 502 genotypes to three gene pools according to their geographical origins (Western, central and eastern Mediterranean).

Associations between 17 SSR markers and fatty acid content of olive oil were determined using the TASSEL program v2.21 and significant associations were detected (Table 5). The number of associations was reduced when the proportions of membership (Q matrix) values estimated from STRUCTURE analysis were included in the analysis as covariates (data not presented). Therefore, significant associations obtained from the structured association analysis using Q matrix of $\mathrm{K}=2$ are given in Table 5. The SSR markers UDO99-39, ssrOeUADCA18, UDO99-06, and ssrOeUA-DCA14 were significantly associated with stearic acid content of olive oil. Association between stearic acid content and ssrOeUA-DCA14 was very high with $\mathrm{P}<0.001$. A highly significant association between GAPU71B and oleic acid was detected. GAPU71B was also associated with linoleic acid, and ssrOeUA-DCA14 was also associated with linolenic acid. It is possible that both oleic and linoleic acids were associated with GAPU71B, because oleic and linoleic acids were highly correlated with each other (Table 3). Similarly, ssrOeUA-DCA14 was associated with both stearic and linolenic acids, because they were also significantly correlated.

Association mapping has been suggested to be used in perennial horticultural plants because of their long juvenile period, high costs of breeding programs and polyploidy (Rikkerink et al., 2007). Although there is no report on the association mapping of agronomic traits in olives, studies on the development of olive core collections suitable for association mapping have been recently reported by several groups (Belaj et al., 2012; El Bakkali et al., 2013). In other horticultural crops, peaches and nectarines, significant associations between agronomic traits and SSR makers were determined in a recent study by Forcada et al. (2013). These authors therefore suggested the use of association mapping as a powerful tool for identifying marker-trait associations and the use of DNA markers associated with agronomic traits in marker-assisted selection in breeding programs.

In summary, SSR markers discriminated olive cultivars from each other efficiently, and clustering results based on 20 SSR markers and nine consensus SSR primers were highly correlated. However, we did not find concordance between clustering of olive cultivars based on SSR markers and fatty acid composition of olive oil. Significant correlations between fatty acid content in olive oil were also observed. Structured association analysis using the GLM procedure in TASSEL v.2.1 detected significant correlation between SSR markers and the fatty acid content in olive oil. To our knowledge, this is the first report on the association of molecular markers with fatty acid profiles in olive oil. These markers could be utilized for the selection of olive cultivars with improved fatty acid compositions. But the degree of association between SSR markers and the content of fatty acids should be confirmed in an independent larger population. 
Table 4. Output of STRUCTURE analysis for Ks from 1 to 10 . $L n$ '(K), $\mid \operatorname{Ln}$ "(K)|, $\Delta \mathrm{K}$ were calculated according to Evanno et al. (2005).

\begin{tabular}{|c|c|c|c|c|c|c|}
\hline K & Reps & Mean $\operatorname{LnP}(\mathrm{K})$ & Stdev LnP(K) & $\operatorname{Ln}^{\prime}(\mathrm{K})$ & $|\mathrm{Ln} "(\mathrm{~K})|$ & $\Delta \mathrm{K}$ \\
\hline 1 & 5 & -1188.84 & 0.40 & - & - & - \\
\hline 2 & 5 & -1195.24 & 6.02 & -6.4 & 55.42 & 9.20 \\
\hline 3 & 5 & -1257.06 & 45.37 & -61.82 & 108.54 & 2.39 \\
\hline 4 & 5 & -1210.34 & 18.77 & 46.72 & 115.60 & 6.16 \\
\hline 5 & 5 & -1279.22 & 31.69 & -68.88 & 19.64 & 0.62 \\
\hline 6 & 5 & -1328.46 & 15.26 & -49.24 & 2.76 & 0.18 \\
\hline 7 & 5 & -1374.94 & 47.76 & -46.48 & 5.10 & 0.11 \\
\hline 8 & 5 & -1416.32 & 129.54 & -41.38 & 29.74 & 0.23 \\
\hline 9 & 5 & -1427.96 & 60.09 & -11.64 & 12.28 & 0.20 \\
\hline 10 & 5 & -1427.32 & 48.67 & 0.64 & - & - \\
\hline
\end{tabular}

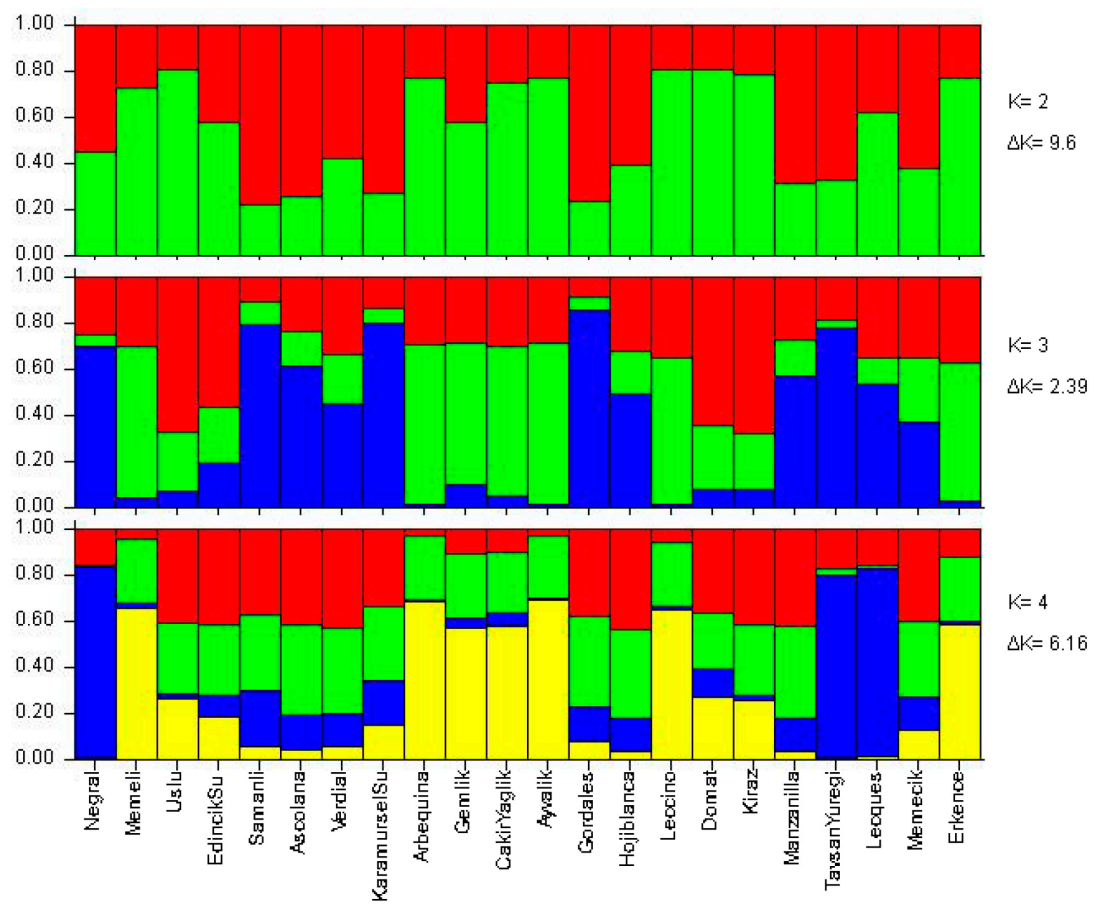

Figure 3. STRUCTURE bar plots based on 17 SSR markers. Different colors represent different gene pools.

Table 5. SSR markers associated with fatty acid contents of olive oil $(K=2, P<0.01)$.

\begin{tabular}{|c|c|c|c|c|c|}
\hline Trait & Locus & F value & P value & $\mathrm{R}^{2}$ & Variation \\
\hline \multirow[t]{4}{*}{ Stearic acid } & UDO99-39 & 126609 & 0.006300 & 0.8932 & 0.9559 \\
\hline & ssrOeUA-DCA18 & 87689 & 0.006900 & 0.9146 & 0.9553 \\
\hline & UDO99-06 & 100261 & 0.001500 & 0.8858 & 0.9357 \\
\hline & ssrOeUA-DCA14 & 145766 & 0.000027 & 0.8270 & 0.8676 \\
\hline Oleic acid & GAPU71B & 114471 & 0.000527 & 0.9314 & 0.9334 \\
\hline Linoleic acid & GAPU71B & 65795 & 0.004300 & 0.8863 & 0.8898 \\
\hline Linolenic acid & ssrOeUA-DCA14 & 43909 & 0.010600 & 0.6247 & 0.6680 \\
\hline
\end{tabular}




\section{ACKNOWLEDGMENTS}

Research supported by the Scientific and Technological Research Council of Turkey (TUBITAK-TOVAG project \#3358). The authors thank General Directorate of Olive Production Station of the Ministry of Agriculture and Rural Affairs, Balikesir, Turkey for providing the fruit samples of olive cultivars.

\section{REFERENCES}

Baldoni L, Cultrera NG, Mariotti R, Ricciolini, et al. (2009). A consensus list of microsatellite markers for olive genotyping. Mol. Breeding 24: 213-231.

Bartolini G, Prevost G, Messeri C and Carignani G (1998). Olive germplasm: cultivars and world-wide collections. FAO Seed and Plant Genetic Resources Service, Plant Production and Protection Division, Roma.

Belaj A, Dominguez-García MC, Atienza SC, Urdíroz NM, et al. (2012) Developing a core collection of olive (Olea europaea L.) based on molecular markers (DArTs, SSRs, SNPs) and agronomic traits. Tree Genet. Genomes 8 : 365-378.

Boskou D (2002). Olive Oil. In: Vegetable Oils in Food Technology Composition, Properties and Uses (Gunstone FD, eds.). CRC Press Blackwell Publishing, Oxford, 244-296.

Bracci T, Busconi M, Fogher C and Sebastiani L (2011). Molecular studies in olive (Olea europaea L.): overview on DNA markers applications and recent advances in genome analysis. Plant Cell Rep. 30: 449-462.

Bradbury PJ, Zhang ZW, Kroon DE, Casstevens RM, et al. (2007). TASSEL: software for association mapping of complex traits in diverse samples. Bioinformatics 23: 2633-2635.

Cantini C, Cimato A and Sani G (1999). Morphological evaluation of olive germplasm present in Tuscany region. Euphytica 109: 173-181.

Carriero F, Fontanazza G, Cellini F and Giorio G (2002). Identification of simple sequence repeats (SSRs) in olive (Olea europaea L.). Theor. Appl. Genet. 104: 301-307.

Cipriani G, Marrazzo MT, Marconi R, Cimato A, et al. (2002). Microsatellite markers isolated in olive (Olea europaea L.) are suitable for individual fingerprinting and reveal polymorphism within ancient cultivars. Theor. Appl. Genet. 104: 223-228.

Corrado G, La Mura M, Ambrosino O, Pugliano G, et al. (2009). Relationships of Campanian olive cultivars: comparative analysis of molecular and phenotypic data. Genome 52: 692-700.

D’Imperio M, Dugo G, Alfa M, Mannina L, et al. (2007). Statistical analysis on Sicilian olive oils. Food Chem. 102: 956-965.

D’Imperio M, Viscosi V, Scarano M-T, D’Andrea M, et al. (2011). Integration between molecular and morphological markers for the exploitation of olive germoplasm (Olea europaea). Sci. Hortic.-Amsterdam 130: 229-240.

De La Rosa R, James CM and Tobutt KR (2002). Isolation and characterization of polymorphic microsatellites in olive $($ Olea europaea L.) and their transferability to other genera in the Oleaceae. Mol. Ecol. Notes 2: 265-267

Di Bella G, Maisano R, La Pera L, Lo Turco V, et al. (2007). Statistical characterization of Sicilian olive oils from the Pelotirana and Maghrebian zones according to the fatty acid profile. J. Agric. Food Chem. 55: 6568-6574.

Díaz A, De la Rosa R, Martín A and Rallo P (2006). Development, characterization and inheritance of new microsatellites in olive (Olea europaea L.) and evaluation of their usefulness in cultivar identification and genetic relationship studies. Tree Genet. Genomes 2: 165-175.

Dice LR (1945). Measures of the amount of ecologic association between species. Ecology 26: 297-302.

Díez CM, Imperato A, Rallo L, Barranco D, et al. (2012). Worldwide core collection of olive cultivars based on simple sequence repeat and morphological markers. Crop Sci. 52: 211-221.

El Bakkali A, Haouane H, Moukhli A, Costes E, et al. (2013). Construction of core collections suitable for association mapping to optimize use of Mediterranean olive (Olea europaea L.) genetic resources. PLoS ONE 8: e61265.

Evanno G, Regnaut S and Goudet J (2005). Detecting the number of clusters of individuals using the software STRUCTURE: a simulation study. Mol. Ecol. 14: 2611-2620.

Fabbri A, Lambardi M and Ozden-Tokatli Y (2009). Olive Breeding. In: Breeding Plantation Tree Crops: Tropical Species (Jain SM and Priyadarshan PM, eds.). Springer, New York, 423-465.

Fendri M, Trujillo I, Trigui A, Rodríguez-García IM, et al. (2010). Simple sequence repeat identification and endocarp characterization of olive tree accessions in a Tunisian germplasm collection. Hortscience 45: 1429-1436.

Forcada CFi, Igartua NOE, Moreno MÁ and Gogorcena Y (2013). Population structure and marker-trait associations for 
pomological traits in peach and nectarine cultivars. Tree Genet. Genomes 9: 331-349.

International Olive Council. Preparation of the fatty acid methyl esters from olive oil and olive-pomace oil. COI/T.20/Doc. 24 2001. Available at [http://www.internationaloliveoil.org]. Accessed May 15, 2011.

Ipek A, Barut E, Gulen H, Oz AT, et al. (2009). SSR analysis demonstrates that olive production in the southern Marmara region in Turkey uses a single genotype. Genet. Mol. Res. 8: 1264-1272.

Ipek A, Barut E, Gulen H and Ipek M (2012). Assessment of inter- and intra-cultivar variations in olive using SSR markers. Sci. Agric. 69: 327-335.

Işık N, Doğanlar S and Frary A (2011). Genetic diversity of Turkish olive varieties assessed by simple sequence repeat and sequence-related amplified polymorphism markers. Crop Sci. 51: 1647-1654.

Kar PK, Srivastava PP, Awasthi AK and Urs SR (2008). Genetic variability and association of ISSR markers with some biochemical traits in mulberry (Morus spp.) genetic resources available in India. Tree Genet. Genomes 4: 75-83.

Kaya HB, Cetin O, Kaya H, Sahin M, et al. (2013) SNP discovery by Illumina-based transcriptome sequencing of the olive and the genetic characterization of Turkish olive genotypes revealed by AFLP, SSR and SNP markers. PLoS ONE 8: e73674.

León L, Martín LM and Rallo L (2004). Phenotypic correlations among agronomic traits in olive progenies. J. Am. Soc. Hortic. Sci. 129: 271-276.

Mailer RJ, Ayton J and Graham K (2010). The influence of growing region, cultivar and harvest timing on the diversity of Australian olive oil. J. Am. Oil Chem. Soc. 87: 877-884.

Mannina L, Dugo G, Salvo F, Cicero L, et al. (2003). Study of the cultivar-composition relationship in Sicilian olive oils by GC, NMR, and statistical methods. J. Agric. Food Chem. 51: 120-127.

Noormohammadi Z, Hosseini-Mazinani M, Trujillo I, Rallo L, et al. (2007). Identification and classification of main Iranian olive cultivars using microsatellite markers. Hortscience. 42: 1545-1550.

Pinelli P, Galardi C, Mulinacci N, Vincieri FF, et al. (2003) Minor polar compound and fatty acid analyses in monocultivar virgin olive oils from Tuscany. Food Chem. 80: 331-336.

Pritchard JK, Stephens M, Rosenberg NA and Donnelly P (2000). Association mapping in structured populations. Am. J. Hum. Genet. 67: 170-181.

Rikkerink EHA, Oraguzie NC and Gardiner SE (2007). Prospects of Association Mapping in Perennial Horticultural Crops. In: Association Mapping in Plants (Oraguzie NC, Rikkerink EHA, Gardiner SE and De Silva HN, eds.). Springer, New York, 249-269.

Sarri V, Baldoni L, Porceddu A, Cultrera NGM, et al. (2006). Microsatellite markers are powerful tools for discriminating among olive cultivars and assigning them to geographically defined populations. Genome 49: 1606-1615.

Schuelke M (2000). An economic method for the fluorescent labeling of PCR fragments. Nat. Biotechnol. 18: 233-234.

Sefc KM, Lopes S, Mendonça D, Dos Santos MR, et al. (2000). Identification of microsatellite loci in olive (Olea europaea) and their characterization in Italian and Iberian olive trees. Mol. Ecol. 9: 1171-1173.

Şeker M, Gül MK, Ipek M, Toplu C, et al. (2008). Screening and comparing tocopherols in the rapeseed (Brassica napus L.) and olive (Olea europaea L.) varieties using high-performance liquid chromatography. Int. J. Food Sci. Nutr. 59: 483-490.

Sneath PHA and Sokal RR (1973). Numerical Taxonomy. Freeman, San Francisco. 